\title{
The Soviet Strategy of Peace in the Asian-Pacific Region
}

V. S. MIASNIKOV

Today the Asian-Pacific direction is the outstanding part of the tireless, many-sided, and purpose-oriented activities carried by the Communist Party of the Soviet Union (CPSU) and the Soviet state in order to improve the international climate. The 27th Party Congress has stressed the growing significance of the Asian-Pacific region in the world policy and the neccessity of activizing efforts in the interests of political settlements of urgent and painful problems so as to take the edge off the military confrontation in various parts of Asia and stabilize the situation there. ${ }^{1}$ The Congress' provisions have been further developed and specified in the Statement by the Soviet Government of April 23, 1986, and in the Vladivostok speech by M. S. Gorbachev who suggested the broad-scale and comprehensive program for creating in the region a sound system of international security as a reliable basis for peaceful interaction and cooperation between the states and the people, and in the Delhi Declaration. The ideas presented in these documents served as a powerful impulse for seeking ways and means of transforming the Asian-Pacific region into a zone of peace and goodneighborly relations.

The expanding cooperation of the Asian and Pacific states with European socialist COMECON member-countries and Cuba is a weighty factor contributing to the improvement of the situation in the region. The countries of the socialist community firmly stand in favor of peaceful efforts of the Soviet Union aimed at preventing nuclear war and militarization of outer space, as well as at establishing security- and confidence-building measures in various parts of the globe. This approach of principle has been confirmed at the June, 1986 Budapest session of the Political Consultative Committee of the Warsaw Treaty member-states, as well as in the course of friendly visits by the toplevel party- and state leaders of the People's Republic of Poland and the German Democratic Republic to the Mongolian People's Republic (MPR), the Democratic People's Republic of Korea (DPRK) and the People's Republic of China (PRC) in September-October, 1986.

The Asian-Pacific direction, being a component of the Soviet communist party and state foreign policy, organically links the global and regional aspects of security, with due and objective consideration of Soviet national 
interests and interests of all states and people in the region.

The Asian part of the Soviet Union (Western and Eastern Siberia, the Far East, the Kazakh SSR and the Central Asian Republics) holds about 75\% of Soviet territory and $30 \%$ of the population; the share of national resources located here is the following: $76 \%$ of coal, about $80 \%$ of natural gas and hydro-resources, more than $70 \%$ of forests, considerable shares of nonferrous and rare metals, etc.

This region produces about $20 \%$ of national product and holds about $25 \%$ of basic productive funds. About $70 \%$ of national production of oil, more than $55 \%$ of natural gas, $15 \%$ of chemical products, and $12 \%$ of machinery is being produced in Soviet Asia.

As planned in the Basic Directions of Economic and Social Development of the USSR for 1986-1990, and Up to the Year of 2000, major territorial-production units, such as Siberian, Sayan, South-Yakutian and others are to be established in the Asian part of the Soviet Union. Besides, it is planned to construct fuel-and-energy plants, coal mines in Kuznetsk and KanskAtchinsk coal regions, and oil-and-gas production centers in Western Siberia.

The Baikal-Amur Railway will be put on regular traffic, and another major railway will connect it with the city of Yakutsk; besides, other big transport connections are to be built up in Soviet Asia. Ferrous and non-ferrous metallurgy, machine-building, large-capacity chemical and other industries will be further developed there.

In his Vladivostok address on July 28, 1986, M.S. Gorbachev formulated a comprehensive plan for long-term development of the Far East within the framework of united regional policy of the Soviet state. This plan aims at creating in the Far East a highly efficient economic complex equipped with its own resources and scientific-production basis, as well as the most appropriate economic structure and a well-developed social sphere.

\section{The Importance of the Asian-Pacific Region}

Many major states of the world, including the USSR, the USA, India, China, Japan, Vietnam, Mexico and Indonesia are situated on the enormous expanses of the Asian-Pacific region spreading over almost half of the earth with a population of more than 2 billion; here lie states which are considered to be medium ones - Canada, the Philippines, Australia and New Zealand, 
and along with them there are tens of smaller and tinier countries.

The region is the area of direct contiguity of the states with different social and political systems: the USSR, the Mongolian People's Republic, the Democratic People's Republic of Korea, the Socialist Republic of Vietnam, The Laos People's Democratic Republic, the People's Republic of Kampuchea as well as the People's Republic of China, on the one hand, and the leading industrial capitalist states, such as the USA, Japan, Canada, Australia, on the other hand.

The interests of the USSR, the USA, China and Japan, with their mighty aggregates of economic and military potentials, get closely entangled in the Asian-Pacific Region. The two major and most promising centres of high technology are situated in the Pacific Basin - the one is on the US Pacific coast, and the other includes Japan, the Newly Industrializing Countries, Asean member-states, South Korea, and China with Taiwan. The USA and Japan take the leading stand in the development of high technologies. Economic growth, opening of new industries, intensification of the "open doors" policy, import of high technology and equipment - such are the most important conditions for expanding the markets in the region.

The share of the Asian-Pacific markets in the world commerce structure has increased from $15.3 \%$ in 1980 up to $17.7 \%$ in 1983.

The shift of the US foreign trade from West Europe to the Asian-Pacific region has played an important part in the growth of regional trade. Up to 1980, West Europe have been the major trade partners of the USA. The situation has changed since 1980: The volume of US trade with the AsianPacific countries (24.6\% of the US foreign trade turn-over) surpassed the US trade with West Europe (24.2\%); the share of the Asian-Pacific region in the US foreign trade turn-over increased up to $29.9 \%$, and that of West Europe went down to $23.7 \%$. Thus the Asian-Pacific region has become the biggest trade market for the USA.

\section{Soviet Initiatives}

The Soviet strategy in the Asian-Pacific region is based on the wellconsidered interests of the Soviet Union and the other states in the region. It consists of the three key components: (i) disarmament; (ii) settlement of regional conflicts; (iii) extension of bilateral contacts with the Asian-Pacific nations and establishment of broad-scaled international cooperation. 
Within the framework of this strategy, the Soviet Union in the recent years has put forward a number of specific and constructive initiatives. The following list recalls some of them:

- The proposal of May 21, 1985 on comprehensive approach to the problems of Asian security and on pooling of efforts by all Asian nations along this direction - up to the holding, in longer-range prospect, of a meeting of the all-Asian forum to exchange views and jointly seeking the constructive solutions.

- The proposal of April 23, 1986 on establishing broad-scale economic, techno-scientific and cultural cooperation among all countries in the Asian-Pacific region on equal basis and irrespective of their social systems; rejection of closed groupings.

- The initiative on convening the Pacific Conference (April 23, 1986; July 28, 1986).

- The expression of preparedness to reciprocate the withdrawal of the U.S. military bases in the Philippines.

- The introduction of proposal on reduction of naval activity.

- The fixed Soviet commitment to disbandment of military alliances and rejection of having military bases in the Asian-Pacific region.

- The proposal to agree upon confidence-building measures.

- The agreement to reduce the "SS-20" medium-range missiles in the Eastern part of the USSR to 100. The USSR agreed to this measure in Reykjavik, October 11-12, 1986, to be linked to progress in the other spheres of disarmament. The linkage issue has been removed later on.

- The declaration of preparedness to reduce Soviet military presence in the Mongolian People's Republic (Vladivostok, July 28, 1986). In 1987, one division was withdrawn from the MPR.

- The declaration of partial withdrawal of troops from Afganistan and preparedness to withdraw all troops in case the foreign intervention is stopped (Vladivostok). The USSR has already withdrawn 6 regiments from the Democratic Republic of Afganistan insofar.

- The idea on multilateral talks on notifications of movements and exercises of land (amphibian), naval and air forces (M. S. Gorbachev in India, November 27, 1986).

- The expression of preparedness to take part in negotiations on guarantees for security of marine communications, including the Straits 
of Malacca (M.S. Gorbachev in India, November 27, 1986).

- The confirmation of interest to resume negotiations on creating the Zone of Peace in the Indian Ocean (M.S. Gorbachev in India, November 27, 1986).

- The expression of Soviet willingness to develop progressive forms of economic ties with the other countries.

The Soviet initiatives, because of their business-like and concrete character, have become a good basis for negotiations on many difficult problems, for a step-by-step progress to elimination of the threat of nuclear disaster, to improved international climate in the Asian-Pacific region and in the entire world.

\section{Asian Security Concept}

In his Vladivostok address M.S. Gorbachev, calling on all Asian and Pacific nations for cooperation for the sake of peace and security, said: "Everyone who is striving for these goals, who hopes for a better future of their peoples, will find us to be benevolent interlocutors and honest partners":2

The Soviet ideas and proposals meet the urgent tasks of solving the most acute problems of the Asian-Pacific region. The Vladivostok concept is the first to bring to the common denominator the rich, many-sided and extremely complicated experience of mutual settlements among Asian countries; this concept enriches the Asian experience by European political achievements and orients it for searching of ways of linking the national interests for the sake of the higher goal, i.e. common security of all countries in the region, their mutually beneficial cooperation and progress.

The Soviet concept of Asian process for peace, security and cooperation is being widely discussed in the U.N. and other international forums, at the meetings among national leaders of Asian, Pacific and other nations, at academic conferences and seminars, in scholarly and journalistic publications. This concept could be realized through the following measures as well:

- apart from the USSR and the PRC, all nuclear powers take the pledge on the non-first use of nuclear weapons in Asia and in the world;

- freezing the level of military, including naval, activity in the region; to 
reduce and to halt arms race (especially nuclear);

- non-use of nuclear weapons against regions and individual countries of Asia that declare the strict observation of their nuclearfree status;

- the adoption by the states not possessing nuclear weapons of the three non-nuclear principles, i.e. not to possess, not to manufacture, not to import nuclear weapons in their respective territories;

- joining the Non-Profileration Treaty by those Asian countries that have not done it so far;

- full halting of nuclear weapons tests, including those in Asian as well as in the Indian and the Pacific Ocean basins, by the nuclear powers;

- rejection, on the part of Asian and Pacific states, of participating in the plans for outer space militarization;

- inadmissibility of creating new and extending the current military blocs in the region;

- arriving at agreements on confidence-building measures in the militarypolitical sphere, including notification on large-scale military exercises (with the invitation of foreign observers) and movements of troops and naval forces;

- establishment of zones of peace, cooperation and good-neighborliness, as well as nuclear-free zones in various regions of Asia and the Pacific/Indian Ocean basins;

- signing of a convention on non-aggression and non-use of force among the countries of Asia and the Pacific/Indian Ocean basins;

- development of equal and mutually beneficial trade-and-economic cooperation on bilateral and multilateral bases;

- non-support, from the outside, of subversive and terrorist armed groups.

It is important to bear in mind that elaboration and implementation of the Asian security concept is, as it was stressed by M.S. Gorbachev, a long-term task. Its realization demands a step-by-step and time-involving approach. The objective can be attained through the concerted efforts of Asian nations based on a comprehensive approach and stage-by-stage consultations; at the initial stage the exchange of views might be bilateral and consequently developed into multilateral, then multilaterally-subregional exchanges which, ultimately, will be carried at the all-Asian level. Such approach enables better consideration of the constructive ideas related to Asian security put forward by the countries in the region; besides, it provides the 
initial discussion of more simple measures that would create prerequisites for more fundamental work on Asian security.

There are many difficult military and political problems in the region. In order to advance to their solution, it is necessary to get rid of the burden of the past, to seek new approaches, guiding oneself by the responsibility for the present and future; to act from the point of new political thinking and clear understanding of the fact that security of each state should not and cannot be provided at the cost of other nations' security. Security can be only general and equal for each nation.

It is absurd and criminal to act in the face of a nuclear threat according to an old, already dead, scheme - what is good for the socialist countries should be rejected. The common danger makes it vital to seek ways and means to providing peace and security by all Asian and Pacific nations, irrespective of their social and economic systems.

The Soviet Union, in putting forward the proposals for improving the military and the political situation in the Asian-Pacific region, does not impose any ready formulae upon the other states. It calls for joint effort in seeking ways to peace on the basis of accumulated experience of taking practical measures for settling the conflict situations and taking collective solutions for the sake of strenghtening peace and security. In this respect it is worth recalling the principles of Pancha Shila and Bandung, the positive diplomatic experience of the truce in Korea, the 1954 Geneva meeting on Indochina, and the Indo-Pakistani agreement in Tashkent. It is the region of Asia that saw the formation of the concept of non-alignment, the movement which now includes more than a hundred nations. It is seeking to come up which its own response to the challenge of time, is actively working for overcoming the world's division into military blocs and is looking for ways and means to diminish the nuclear threat.

The Soviet Union supports the initiatives of other states in the region, since they, in our view, are aimed at detente, strengthening of peace and security, as well as development of international cooperation in the Asian-Pacific region. Thus, the USSR

- has joined the Rarotonga Treaty;

- supports, as mentioned above, the idea of the Peace Zone in the Indian Ocean;

- approves of proposals on nuclear-free zones in Korea and Southeast Asia; 
- supports the initiatives of the Indochina states related to establishment of the zone of peace, cooperation and stability in Southeast Asia; signing of treaties on peaceful coexistence of Vietnem, Laos and Kampuchea with China; normalization of relations between the U.S. and Indochina, etc,;

- approves the MPR's proposal about the convention on mutual nonaggression and non-use of force in the relations among the Asian and Pacific nations;

- views as constructive the DPRK's proposals on peaceful and independent unification of Korea.

Today we have enough reasons to conclude that it is not only necessary but possible to switch the Asian-Pacific region to the process of creating the comprehensive system of international security.

To attain military and, consequently, political detente in the region, it is necessary to join efforts of all Asian and Pacific countries in solving many vital problems. The settlement of military conflict situations pregnant with dangerous tensions among the states could become a primary step in this direction.

It has become a kind of habit in the West to use various allegations on the growth of "Soviet military threat" to disguise and to justify the increased military build-up by the USA and its partners in the Asian Pacific region.

There is no doubt that the USSR, as well as the USA and the PRC, is, militarily, the mightiest state in the region. But the fact also is that the USSR is an Asian and Pacific country. The dangerous military and political situation in the region bears on its national interests directly and makes it take retalitory measures. These measures are adequate to the real danger and are designed just to maintain the regional military balance in strict abidance with the principles of parity and equal security. In this respect one should pay serious attention to the following abstract from M.S. Gorbachev's speech in Vladivostok where he said: "Let me state with all responsibility: we are not doing anything and shall not do anything over and above the level that corresponds to the minimal requirements of our defence, the defence of our friends and allies, especially in the light of the American military activity not far from our and their frontiers". ${ }^{3}$

The Soviet side believes that despite different political systems, ideologies and views, the Asian and Pacific nations are bound by common vital interests. Under growing interdependence of the states it is much more 
difficult, if ever possible, to solve the outstanding tasks alone or within a closed group of states; it is necessary to join efforts of all countries in the region, irrespective of their social and political systems.

The elimination of nuclear and chemical weapons by the end of the current century, and the prevention of space militarization, as proposed by the Soviet Union, would rid the nations of the world, including the AsianPacific region, of the fear of nuclear and chemical threat, bring security of the states to a qualitatively new level and contribute to favorable conditions for mutually beneficial cooperation. ${ }^{4}$

The Soviet Union also proposes to carry bilateral and multilateral consultations for attaining decisions on disputed issues and improving understanding and confidence which would help in convening the all-Asian forum for joint search of constructive decisions. In this respect it would be very useful, for example, to carry a separate conference of Pacific countries on security, including economic security issues. The confidence-building measures and the reduction of naval activity would also have a most stabilizing effect.

The Korean peninsula is now a hotbed of political and military tension in the Asian-Pacific region. Today there is an urgency and a possibility for lessening such tensions and for starting the move along the road of solving the national problem of the entire Korean people, on the basis of the constructive proposals put forward by the DPRK.

The establishment of mutually acceptable relations between the countries of Indochina (Vietnam, Laos, Kampuchea) and the ASEAN (Indonesia, the Philippines, Thailand, Malaysia, Singapore, Brunei) is also one of the most crucial and urgent problems in the region. Normalizing the situation around Kampuchea is becoming the top-priority task in the region. With its suffering the Kampuchean people has gained the right to choose friends and allies for itself and to determine its fate and future. As for Vietnamese volunteers in Kampuchea, it is known that their withdrawal has started already and is planned to be completed in 1990. Here, like in many other problems of Southeast Asia, much depends on the normalization of Sino-Vietnamese relations.

\section{Nuclear-Free Zone}

To put up a barrier in the way of the proliferation and build-up of nuclear 
weapons in Asia and the Pacific Ocean is a task of paramount significance; and in this context it is urgent to stress the initiative of the Soviet Union who pledged not to increase the number of medium-range nuclear missiles in the Asian part of the USSR.

Proclaiming the Southern part of the Pacific a nuclear-free zone is, naturally, a serious step towards lessening the nuclear danger in the region. The treaty on the nuclear-free zone was signed by ten South Pacific Forum member-states on August 6, 1985. The Soviet Union supported proclaiming the South Pacific a nuclear-free zone and urged all nuclear powers to guarantee its status in a unilateral or a multilateral way. China has also spoken in favor of this nuclear-free zone.

The implementation of the proposal of the DPRK for the creation of a nuclear-free zone on the Korean peninsula could be a serious contribution to diminishing a nuclear threat in the Asian-Pacific region. The well-deserved attention was aroused by the idea of creating such a zone in Southeast Asia.

The rising activity of navies, above all nuclear-armed vessels, is a serious source of tension in the region. The Soviet Union has already spoken in favor of considering the question of balanced reduction of a number of ships within the navies of major powers, with special attention to air-carriers since the latter bring the most destabilizing effect into the situation.

The security interests of the peoples of Asia and the Pacific urge for crucial reduction in scale and number of naval exercises that are carried in the region with increasing activity.

Time has long come to switch to a practical plane the discussion of confidence-building measures and non-use of force in the region. The start could be made, for instance, from measures for security of sea lanes in the Pacific and for the prevention of international terrorism. The Soviet Union has already suggested that a conference to discuss and work out such measures could be held in one of the Soviet maritime cities.

The efforts by the Non-Aligned Countries aimed at the speediest implementation of the UN Declaration on proclaiming the Indian Ocean a peace zone and the holding of the pertinent international conference in 1988, deserve an active support. The Soviet Union suggests that until the conference is convened, all states using the Indian Ocean basin for their marine traffic should abstain from any steps that might aggravate the situation in the region. What is meant is not to send large naval units there, not to carry military exercises, not to extend and not to modernize military 
bases of non-coastal states that have such bases there.

It is no less but maybe even more important for the Asian-Pacific region than for the rest of the world, to see radical reduction of armed forces and conventional weapons in Asia to the limits of reasonable sufficiency. By economic calculations, about $80 \%$ of world military expenditures are allocated for conventional armaments.

Under present conditions this, not at all simple, problem should be tackled gradually, stage-by-stage, by starting from one area, say the Far East. It may be reminded in this respect, that the Soviet Union has expressed its preparedness to discuss with the PRC concrete steps aimed at proportionate lowering of the level of land forces.

It is absolutely obvious that only through joint effort and persistenly patient search for mutually acceptable solutions the military and the political situation in this vast region of the globe can be improved, and security for all peoples living there can be attained.

The Soviet Union has proposed to start an extensive exchange of views among all interested countries in this part of the world on establishing equal, mutually beneficial and steady trade-and economic cooperation and interaction in the fields of technology, science and culture. This cooperation could encompass such aspects as development of productive forces, training of personnel, utilization of new, including nuclear, energy resources, modification of transport and communication means, elaboration of new forms of trade, economic and financial cooperation with due consideration of the developing countries' interests, exchange of science and technology data, development of environmental measures and rational use of bio-mineral resources in seas and oceans, peaceful space research in common interests, joint health project, counter-action against natural disasters and their aftermath.

\section{USSR and Major Asian-Pacific Powers}

The United States is one of the great Pacific powers. Unlike the rightist forces in the US who try to neglect the international and political role of the Soviet Union in the Asian-Pacific region, the USSR recognizes the legitimate interests of the USA in the region and considers them in its policy. The Soviet Union proceeds from the understanding that in the interests of peace and cooperation in the Pacific, both countries should seek ways to agree upon 
their positions and to work out mutually acceptable agreements in all spheres of relations.

There are large potentials for considerable growth of trade and economic contacts between the Soviet Far East (expecially when considering plans for its accelerated development) and the West coast of the United States. It is possible to elaborate large-scale projects for long-term economic cooperation on bilateral and multilateral bases, with participation, besides the United States, of, say, Japan and China; such projects could include constructions of joint ventures, joint exploration of coal, oil, natural gas and other resources.

The establishment of good-neighborly relations between the Soviet Union and Japan is most important for strengthening peace and security in the region. The Soviet Union stands in favor of the most active Japanese participation in the process of improvement of the world situation. The constructive role of Japan in the world politics can grow only if coupled with its positive contribution to the process of peace, security and multilateral cooperation in the Asian-Pacific region.

In this context, the truly good-neighborly relations between the Soviet Union and Japan would be tremendously important. Both countries possess really enormous potential for political, economic, scientific, technological, humanitarian and other kinds of cooperation. High intellectual potentials of the Soviet Union and Japan could provide for most efficient joint work on the peaceful use of atomic energy and outer space, investigation of rational use and reproduction of biominerals resources of the world ocean, etc., for the benefit of the two nations.

\section{Relations Between China and the USSR}

The notable rapprochement between the Soviet and Chinese attitudes on international security matters that is taking place in parallel and connection with the improvement of Soviet-Chinese relations considerably enlarges the material basis for peace in the Asian-Pacific region. The indirect interaction between the USSR and the PRC, based on their rapprochement, in striving against the increasing military threat contributes to active consolidation of anti-imperialist, social and other forces in the region. Today various "streams" and forces within this movement gain parallel support on the part of the two great powers, i.e, the Soviet Union and China. 
Objective dimensions and goals of the Soviet-Chinese normalization prove that it does not take place at the cost of Soviet or Chinese relations with the third countries, and that its further progress does not make it necessary to worsen the two countries relations with other states. Due to this only circumstance the progress of the Soviet Union and China towards good neighborliness creates new opportunities for international detente in the region. Such progress has started and is continuing against the background of China's now friendly relations with many states in the region, primarily the USA and Japan. Today, with some reservations of course, this friendship may be seen as a positive contribution to the settlement of the inter-system relations. This is an extremely important factor, since the fate of peace and security, in the Asian-Pacific region in particular, depends mainly and exactly on the state of the inter-system relations on the global and the regional levels.

Apart from anything else, the Sino-Soviet improvement seems to open possibilities for the dialogue among the three nuclear powers, i.e. the USSR, the USA and the PRC, on the reduction of level of military confrontation in the Asian-Pacific region. The fact is that today China is more than ever in the recent 25 years objectively able to act as a constructive and independent force on the international stage.

China's involvement in the talks on these issues, from the point of initiation of such talks, seems to be useful for at least two reasons. First, this would remove Beijing's concern about the discussions on cardinal problems of strenghthening the regional security without China's direct participation; second, with due consideration of China's prestige in Asia and the real dimensions of her foreign policy, one can assume that China's participation since the moment of initiation of the talks among the nuclear powers would be favorable for greater confidence among various groups of countries in the Asian-Pacific region.

The Soviet-Chinese normalization brings about promising opportunities for a general positive shift towards turning the entire Asian-Pacific region into a zone of peace and efficient international cooperation. Not to miss these opportunities, this historical change, implies taking a real step along the direction of new political thinking.

Soviet-Chinese relations are one of the first priorities in Soviet foreign policy for a number of reasons.

First, China is a great country, and it is impossible to solve the urgent international problems and to attain lasting peace on our planet and in the 
Asian-Pacific region in particular, without cooperation or interaction with China.

Second, the PRC is a neighbor of the USSR; the Soviet-Chinese border stretches for 7.5 thousand kilometers and is the lengthiest in the world. The two nations, by the will of fate, will live as next-door neighbors forever.

Third, China, as well as the Soviet Union, goes along the socialist path; both have similar objectives of constructing a developed and prosperous society based on the principles of social justice. That's why the USSR believes that the former Soviet-Chinese disagreements do not have any long-term or objective foundation. They were brought about by historical reasons and subjective errors and may be related to the difficult process of socialist formation. Still, in major terms, socialist countries can and must maintain relations of harmony and friendship.

In the recent four or five years there has been notable improvement in Soviet-Chinese relations, characterized at present by the following:

The bilateral negotiations on various aspects of inter-state relations are put on a regular basis. From October 1982 on, there have been 10 rounds of political consultations at the level of the USSR and the PRC governments' special representatives of the rank of deputy foreign ministers (the last round was held in April, 1987 in Moscow). Issues of bilateral relations and some international problems are on the agenda of the consultations, which, in their turn, contribute to development of bilateral contracts in various fields. Border consultations have been resumed also.

In 1985 there was established the Joint Soviet-Chinese Commission on economic, trade and techno-scientific ties; the first session was held in Beijing in March, 1986; Moscow hosted the second session in May, 1987.

The volume of Soviet-Chinese trade in 1986 was 1.7 billion roubles. Border trade is also being developed (about 28 mill. roubles in 1986). Under the agreement of June 10,1986, the volume of Soviet-Chinese trade should be increased up to 3 billion roubles, i.e. almost two-fold for the 5 years. The agreement also envisages Soviet assistance in construction of 7 and modification of 17 plants in China in such fields as energy, ferrous and nonferrous metallurgy, machine-building, coal industry, and transport. In 1986 there were put forward other proposals on cooperation in construction and updating of Chinese plants that are now being considered by both sides.

The State Planning Commissions of the USSR and the PRC signed an agreement on cooperation in planning activity. After signing of the new Consular convention, the USSR and the PRC opened their Consulates- 
General in Shanghai and Leningrad. Regular work and sessions are carried out by the Joint Soviet-Chinese Commission on navigation in the border sections of the Amur basin rivers, subcommissions and working groups on scientific and technical cooperation, transport, etc. The two states exchange students, trainees and post-graduates (up to 200-300 on each side annually).

The cultural and social contacts between the Soviet Union and China are being expanded, with successfull realization of the plan for cultural cooperation in 1986-1987. The two sides exchange delegations of writers and composers, art exhibitions, theater- and art- troups, delegations and professional tourist groups sponsored by the Friendship Societies.

Still, there are some difficult issues left in the Soviet-Chinese relations. Because of the well-known "three obstacles", the PRC does not consider the relations with the Soviet Union as normalized. We admit that there do exist problems around Kampuchea and Afghanistan and we are prepared to attend to their settlement; in this context we are applying efforts as mentioned above. But, in the Soviet view, these are international problems and they should not hamper the Soviet-Chinese normalization, bilateral summit meetings or political interaction between the Soviet Union and China in respect to international issues involving the coinciding interests of both.

Noteworthy is the growing number of the regional problems viewed by the Soviet Union and China from close or even identical positions:

- The PRC, as well as the Soviet Union, stands in favor of full elimination of nuclear weapons and foreign military bases in Asia and in the Pacific Ocean.

- Both countries support the DPRK's efforts for peaceful settlement on the Korean peninsula.

- Both the Soviet Union and China joined the Rarotonga Treaty.

- Both states call for broad economic cooperation among the nations in the Asian-Pacific region.

Besides, there are quite a few common aspects in the Soviet and Chinese approaches to global political matters and to settlements of the regional conflicts in the other parts of the globe:

- Both nations stand for total and full disarmament. 
- The PRC and the USSR took a pledge on the non-first use of nuclear weapons.

- Both countries stand against arms race in outer space.

- The Soviet Union and China extend their support to the peoples of the Arab East, South Africa and Central America struggling for their rights.

- Both countries support the developing countries striving for more just economic relations with the developed countries.

Due to commonality of views, the representatives of the USSR and the PRC in the U.N. vote identically on $70 \%$ of the issues.

Naturally, we do not neglect the still existing Soviet-Chinese differences in the international affairs. The Soviet Union is willing and is taking efforts to overcome these differences. Not at all does it have the objective of exerting any effect upon the established system of China's international relations. The Soviet Union fully respects China's independent policy as well as its willingness to maintain good relations with Japan, the USA and other states. We understand the natural aspiration of the PRC to a higher international role corresponding to its population, and economic and cultural potential. The Soviet Union would like to see China as a prosperous country, actively contributing to strenghthening world peace and development of international cooperation.

The Soviet and Chinese views on some issues are quite likely not to coincide in the future, but such prospect in no way is intimidating. In our diversified complex world with thousands and thousands of political, economic, social, cultural, historical, ecological and many other problems such differences are quite natural. We just have to learn how to solve them in the spirit of friendship and mutual respect. That's what we are heading for.

Professor Dr. V. S. Miasnikov is Deputy-Director of the Institute of Far Eastern Studies, Moscow.

\section{NOTES}

$1 \mathrm{M}$. Gorbachev, Political Report of the CPSU Central Committee to the 27th Party Congress (Moscow: Novosti Press Agency, 1986), pp. 86-87.
2 Far Eastern Affairs, 1987, No. 1, p. 20.

3 Far Eastern Affairs, 1987, No. 1, p. 17.

4 See Pravda, April 24, 1986. 